Neurovascular

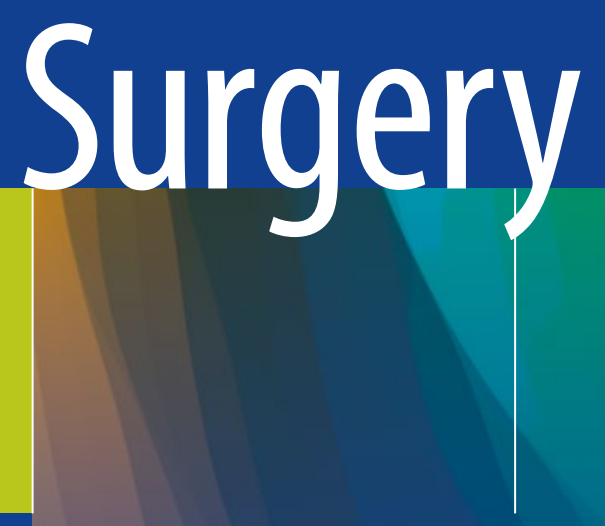

Surgical Approaches for Neurovascular Diseases

Julius July

Eka J. Wahjoepramono

Editors

Springer Open 
Neurovascular Surgery 
Julius July • Eka J. Wahjoepramono Editors

Neurovascular Surgery

Surgical Approaches for Neurovascular Diseases

Springer Open 
Editors

Julius July

Department of Neurosurgery

Pelita Harapan University

Tangerang

Indonesia
Eka J. Wahjoepramono

Department of Neurosurgery

Pelita Harapan University

Tangerang

Indonesia

This book is an open access publication.

ISBN 978-981-10-8949-7 ISBN 978-981-10-8950-3 (eBook)

https://doi.org/10.1007/978-981-10-8950-3

Library of Congress Control Number: 2018956495

(C) The Editor(s) (if applicable) and The Author(s) 2019

Open Access This book is licensed under the terms of the Creative Commons Attribution 4.0 International License (http://creativecommons.org/licenses/by/4.0/), which permits use, sharing, adaptation, distribution and reproduction in any medium or format, as long as you give appropriate credit to the original author(s) and the source, provide a link to the Creative Commons license and indicate if changes were made.

The images or other third party material in this book are included in the book's Creative Commons license, unless indicated otherwise in a credit line to the material. If material is not included in the book's Creative Commons license and your intended use is not permitted by statutory regulation or exceeds the permitted use, you will need to obtain permission directly from the copyright holder.

The use of general descriptive names, registered names, trademarks, service marks, etc. in this publication does not imply, even in the absence of a specific statement, that such names are exempt from the relevant protective laws and regulations and therefore free for general use.

The publisher, the authors, and the editors are safe to assume that the advice and information in this book are believed to be true and accurate at the date of publication. Neither the publisher nor the authors or the editors give a warranty, express or implied, with respect to the material contained herein or for any errors or omissions that may have been made. The publisher remains neutral with regard to jurisdictional claims in published maps and institutional affiliations.

This Springer imprint is published by the registered company Springer Nature Singapore Pte Ltd. The registered company address is: 152 Beach Road, \#21-01/04 Gateway East, Singapore 189721, Singapore 


\section{Preface}

This book is a compilation of the practical details and practices of the key steps in doing a neurosurgery for residents and young neurosurgeons, which provides a variety of illustrations of the intraoperative photographs that will help neurosurgeons gain a better understanding in the neurosurgery field. The chapters are grouped into three parts. The first part, from Chap. 1 through 10, is about an approach-based topic which focuses primarily on the commonly used approach for vascular lesion. The second part, from Chap. 11 through 25 , consists of a variety of surgery procedures for specific location of vascular lesion or specific pathology.

The first two groups provide the expert's trick on how to avoid complications during the surgery and some additional expert opinions. The third part, from Chap. 26 through 32, compiles the miscellaneous information that contains some supportive knowledge, technology improvement, and other options of treatment modalities. The detailed and step-by-step approach presented in each chapter with the intraoperative pictures will help provide guidance, especially for many young neurosurgeons who are in the areas with limited resources.

It is a goal to keep this book simple and practical by providing the strength of basic surgical anatomy orientation. Each specific pathology or location requires different approaches that have been addressed in some of the chapters. Every thought and idea shared in the chapters of this book is written by experts who have been in their fields, practicing for many years. Every contributor represents his or her region's best practices that have been proven true based from the neurosurgery results and testimonies they collected and experienced.

We would like to say many thanks to all the contributors who unselfishly shared their expertise and time and to the Springer Publishing Co., which made the publication possible, especially to Dr. Eti Dinesh who encouraged the editors to get this book published. Our gratitude to all the people who are involved in the preparation, from the moment this book was conceptualized. A special thanks to Dr. Megah Indrasari whose support motivated us to believe in what we see for the future of neurosurgery and to never give up on our dreams. And to all our friends who journeyed along with us through this project. 
May this book serve as a quick and practical reference for many young neurosurgeons and to those who may need it, in all parts of the world.

Tangerang, Indonesia

Tangerang, Indonesia
Julius July

Eka J. Wahjoepramono 


\section{Contents}

\section{Part I Surgical Approaches}

1 Pterional Approach . . . . . . . . . . . . . . . . 3

Sophie Peeters and Julius July

2 Eyebrow Keyhole Approach in Aneurysm Surgery . . . . . . . 11

Asra Al Fauzi, Nur Setiawan Suroto, and

Abdul Hafid Bajamal

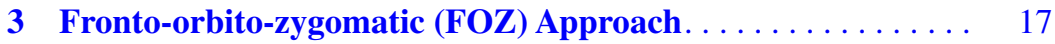

Imad N. Kanaan

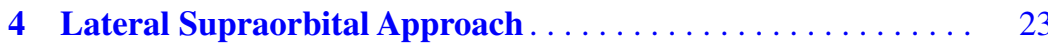

Juha Hernesniemi, Hugo Andrade-Barazarte, Rosalia Duarte,

Joseph Serrone, and Ferzat Hijazy

5 Interhemispheric Approach

Alberto Feletti, Dilshod Mamadaliev, Tushit Mewada,

Kei Yamashiro, Yasuhiro Yamada, Tsukasa Kawase, and Yoko Kato

6 Subtemporal Approach.

Yong Bae Kim and Kyu Sung Lee

7 Lateral Suboccipital Approach (Retrosigmoid)

Senanur Gulec, Francesca Spedicato, Ferry Senjaya, and Julius July

8 Transmastoid Approach for Retrolabyrinthine and Translabyrinthine

Tetsuro Sameshima

9 Dissection of Extended Middle Fossa and Anterior

Petrosectomy Approach .

Tetsuro Sameshima

10 Basic Endovascular Technique for Aneurysm Coiling 


\title{
Eyebrow Keyhole Approach in Aneurysm Surgery
}

\author{
Asra Al Fauzi, Nur Setiawan Suroto, \\ and Abdul Hafid Bajamal
}

\subsection{Basic Consept}

The concept of keyhole neurosurgery is not only to perform small incision and reduce the craniotomy size for the sake of a small opening as we called "keyhole," but it is rather to make "minimum craniotomy" required to access deep intracranial lesions at the end of the route. Standard craniotomy forms a "funnel-shaped surgical corridor" to reach deeper area of the brain. In contrast, keyhole mini craniotomy forms a "reverse funnel-shaped surgical corridor" that provides adequate working space through a small incision and bone window to reach the target. The concept of this approach is that the deep area of the brain can be accessed through smaller craniotomy since the superficial optical field is widened if the size of craniotomy is bigger (Fig. 2.1).

Intracranial aneurysm surgery using eyebrow keyhole approach has been reported by Van Lindert and Perneczky in 1998, and since then, this approach has been accepted as minimally invasive approach for aneurysm clipping surgery in addition to the existing standard approach.

\subsection{Preoperative Planning}

The planning and execution of the approach play a critical role in performing this keyhole surgery. The smaller the craniotomy, the greater the need for precise planning and self-made completion of the approach because the corridor of surgical dissection cannot be changed during the procedure.

It is necessary to have preoperative consideration about the size and aneurysm dome projection, aneurysm location, perforating arteries, surrounding important structures, and how to plan the bone flap. Using excellent diagnostic facilities of CT, MRI, and digital subtraction angiography (DSA), one has today the possibility to demonstrate small details and specific anatomical orientation of the lesion related with surgical planning. In our experience, preoperative planning for eyebrow keyhole surgery is could be mainly by using and rely on 3D CT angiography (3D-CTA). The $3 \mathrm{D}$ reconstruction images maybe able to shows from the skin, then skull, cerebral arteries and veins, including size and shape of the aneurysm. The preoperative planning of the keyhole craniotomy can be simulated with 3D-CTA (Fig. 2.2). 

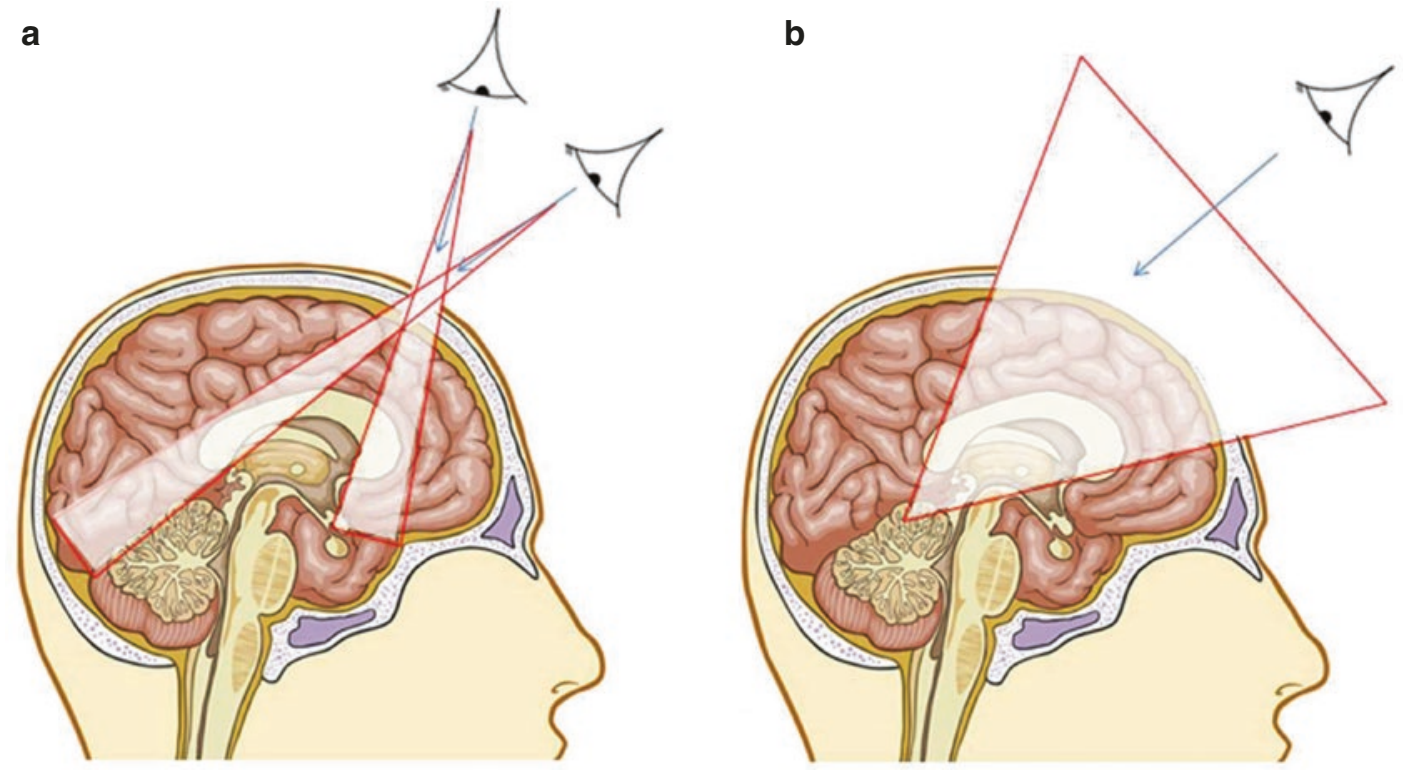

Fig. 2.1 Concept of surgical corridors in keyhole craniotomy. (a) Keyhole craniotomy with "reverse funnel-shaped" corridor, (b) macrocraniotomy with "funnel-shaped" corridor

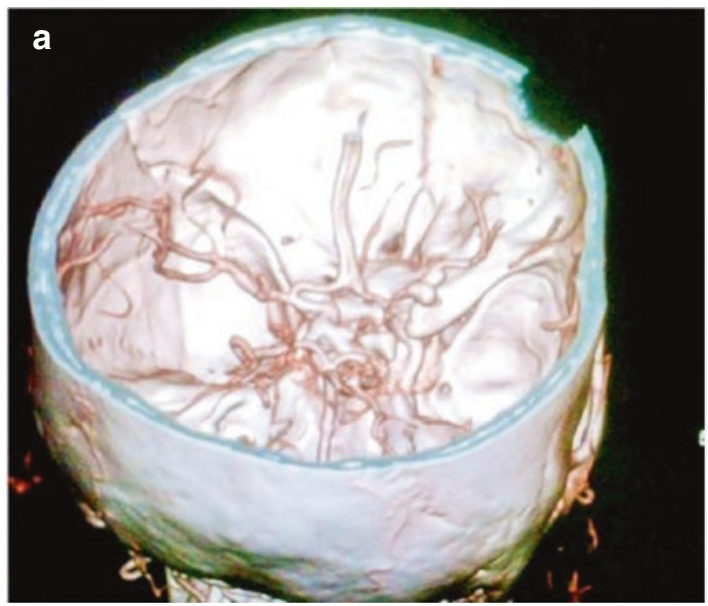

Fig. 2.2 Preoperative planning with 3D CTA images showing the skull, cerebral arteries, and aneurysm pathology. (a) The supraorbital keyhole craniotomy and its rela-

\subsection{Step of the Approach}

\subsubsection{Positioning and Preparation}

The surgeon must plan and perform the proper positioning of the patient by himself. Self-made preparation and positioning are essential for creating keyhole craniotomies. After the patient is

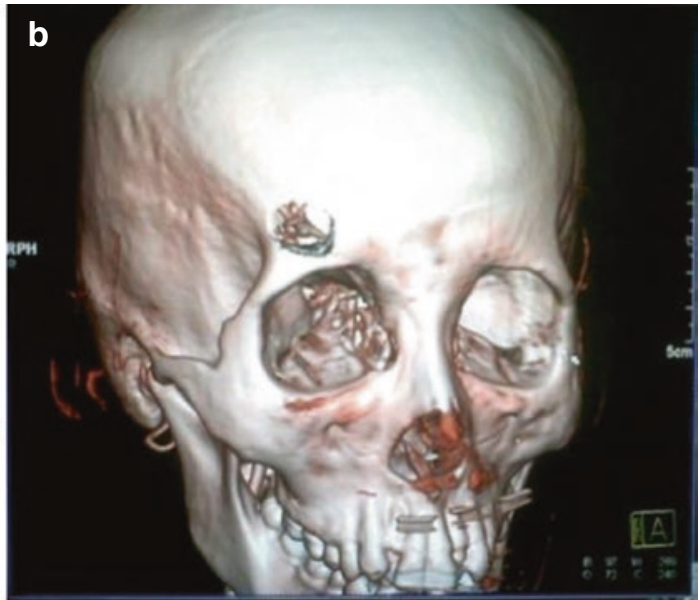

tionship to the aneurysm are well visualized. (b) The supraorbital craniotomy with the lesion is prepared at various angles to have an optimal microsurgical visualization

anesthetized, the patient head is positioned in supine with head holder, and the head is higher up approximately $15^{\circ}$ to facilitate venous drainage. A slightly chin-up position is preferable to support the frontal lobe that will slightly fall down according to the gravity force. The degree of head rotation should be determined by preoperative $3 \mathrm{D}$ simulation, but generally the head is 


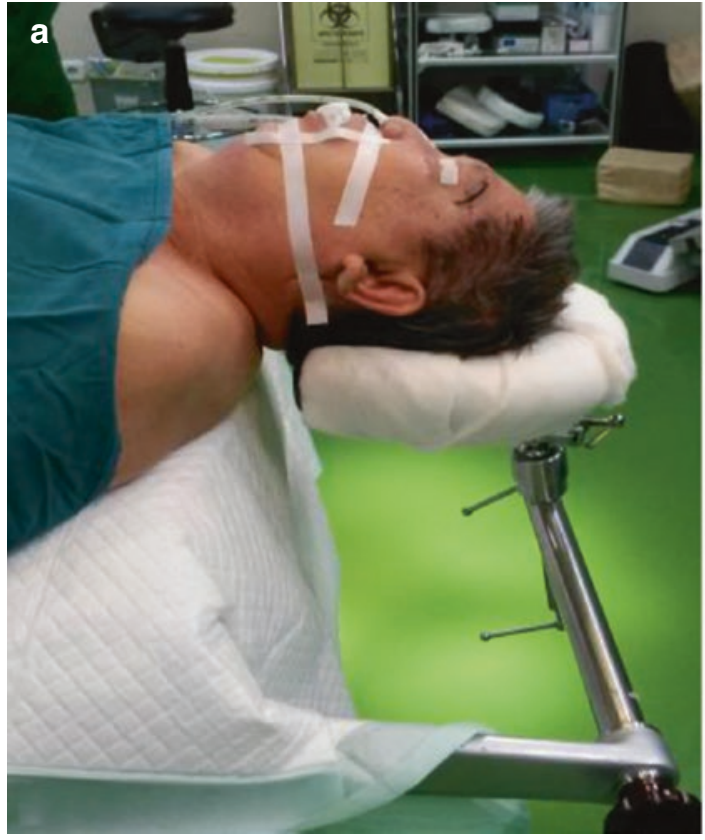

Fig. 2.3 Supine positioning of the patient, slightly extended and the head is turned to contralateral, and depend on aneurysm location. In most cases, the headrest

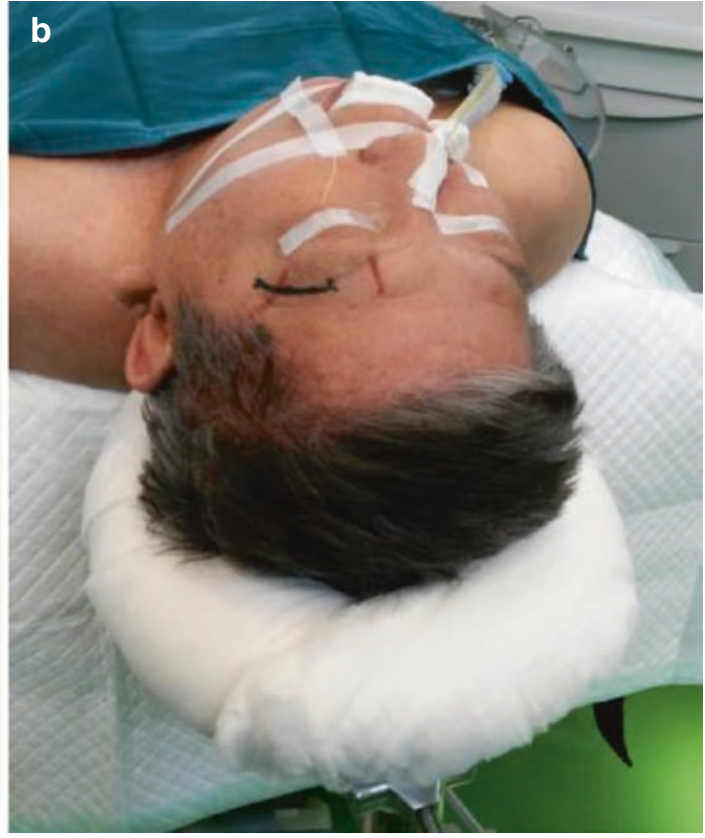

with soft cushion is used for a brief preparation; the use of head fixation clamp is not necessary

subcutaneously to obtain optimal exposure to surrounding muscles. We could clearly identify the frontal, orbicularis oculi and temporal muscles. After dividing the muscular layers gently, we have to identify pericranium at supraorbital edge, and it is cut perpendicularly following superior temporal line to get good bone exposure.

Skin flaps should be gently retracted with three or four temporary stiches at each upper and lower side of the flaps. The frontal muscle should be retracted upward, and the temporal muscle is detached gently from the attachment and retracted laterally to expose ipsilateral temporal line, and then keyhole area is exposed. Gentle detachment and pulling of the muscle are important to prevent local postoperative hematoma (Fig. 2.4).

\subsubsection{Mini Craniotomy and Dural Incision}

Making a single frontobasal burr hole at the frontozygomatic point just behind the temporal line by using high-speed drill. The placement and direction of the drilling procedure should be in correct manto avoid damaging hair follicles and surrounding tissues. After skin incision, skin flap is dissected 


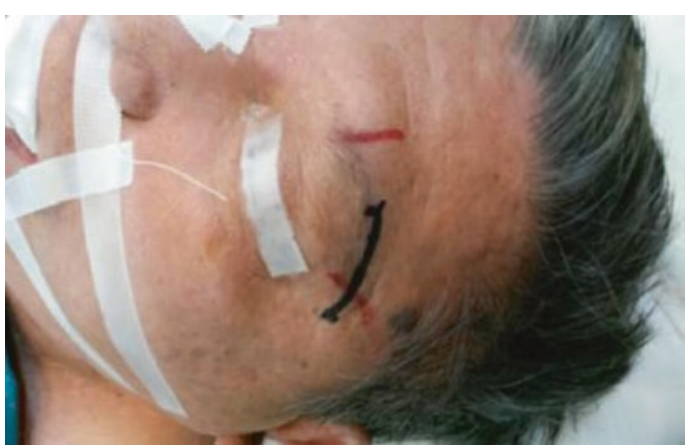

Fig. 2.4 Skin cut from the lateral border of supraorbital notch and extending a few millimeters from the eyebrow line to reach the temporal line

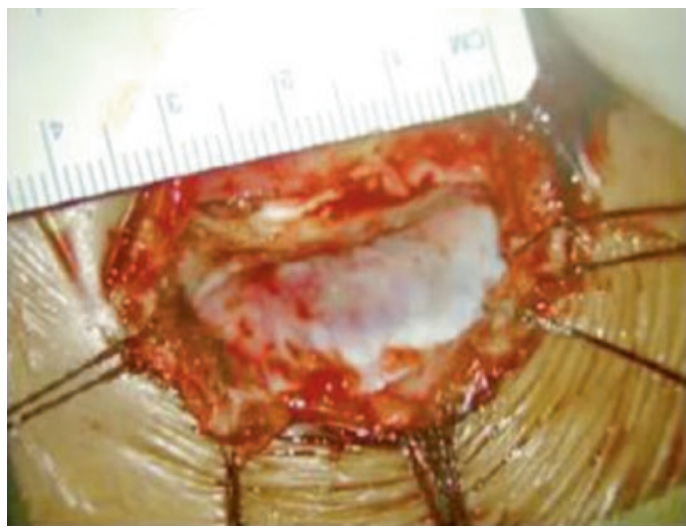

Fig. 2.5 Supraorbital keyhole craniotomy with a width of 25-30 $\mathrm{mm}$ and a height of $15-25 \mathrm{~mm}$

ner. Wrong direction during drilling can cause the drill going into the orbit, while we actually want it to go to the anterior frontal floor. The craniotomy flap is then performed with high-speed craniotomy, starting from lateral orbital rim and following the

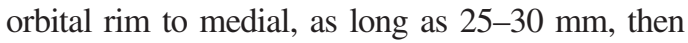
curving cranially about $15-25 \mathrm{~mm}$, and cutting back to the burr hole site, thus creating a small bone flap. An important point is the bone cut should be very close and approaching orbital roof and if necessary additional drilling to make any prominence at the frontal floor totally flat. This may provide a few millimeters more exposure and avoid the bony prominence to obstruct surgical visualization and facilitate optimal microsurgical maneuvers using microscope and microinstruments (Fig. 2.5).

Opening the dura with semicircular shape and the base parallel along the orbital rim. The dura flap is reflected basally and fixed downward with three or four sutures so that dural window is formed in optimal opening following craniotomy corridor (Fig. 2.6).

\subsubsection{Intradural Dissection}

After opening the dura, the first-step maneuver is to gently remove sufficient cerebrospinal fluid by opening the arachnoid membrane through the chiasmatic and carotid cistern or furthermore to Sylvian fissure. Ventricular puncture and drainage sometimes may be needed in case of brain edema; the authors only use the lumbar spinal drain for very selective cases. With adequate drainage of CSF (cerebrospinal fluid), the brain becomes relaxed, then a brain spatula is put in the frontal lobe, and the purpose is to protect the cortex and not to retract the cortex. With this efficient and adequate surgical corridor, we can get to the aneurysm precisely and avoid extensive cortical retraction (Fig. 2.7).

\subsubsection{Closure and Bone Flap Replacement}

After the intracranial procedure is performed, the next step is filling the intradural space with warm normal saline. Close the dura with watertight and interrupted sutures, and then make sure that any defects are well repaired. If the frontal sinus opened during the surgery, it is a must to seal off the frontal sinus to avoid postoperative infection. Bone flap is placed back, and hold it with mini plates and be careful not to penetrate frontal sinus by the screws. Authors prefer using three mini plate fixations at medial, lateral, and upper part of craniotomy to make sure a strong fixation to prevent postoperative deformity. Reapproximate the temporal muscle to zygoma by one or two sutures. After final hemostasis control, reapproximate the subcutaneous layer by interrupted sutures; then the skin is also closed by interrupted sutures in the eyebrow (Fig. 2.8). 

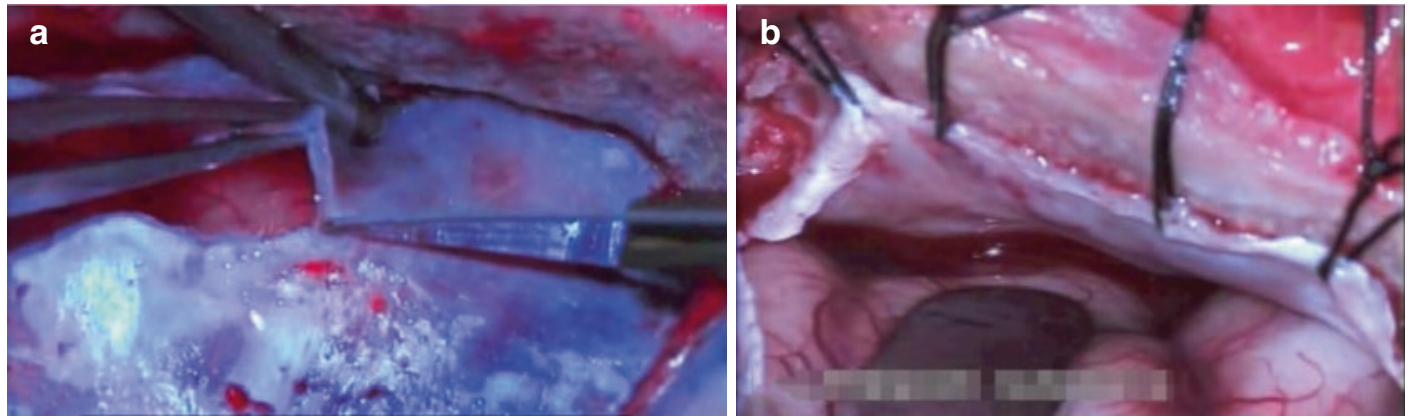

Fig. 2.6 (a) Opening the dura in a curved fashion toward the frontal base, (b) optimal surgical corridor to the skull base after dural opening
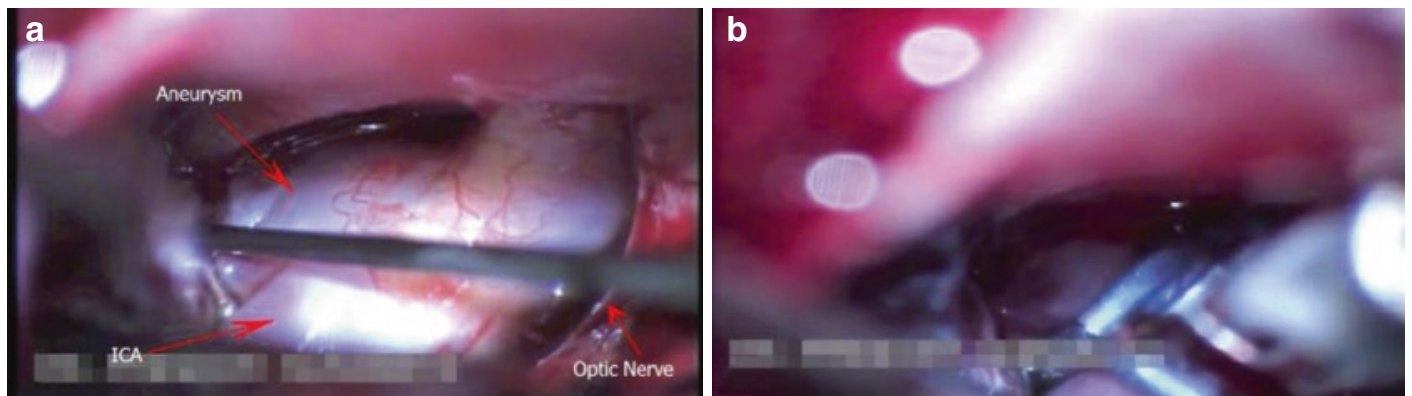

Fig. 2.7 (a) Intradural dissection and securing the aneurysm using microinstruments, (b) clipping procedure

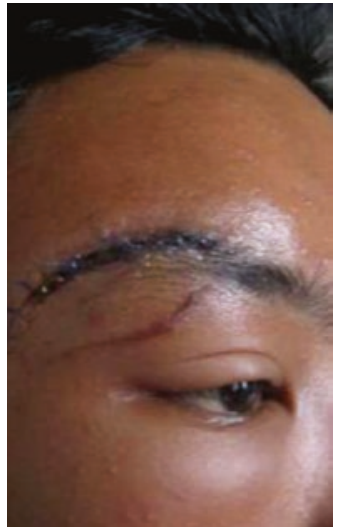

Fig. 2.8 The skin is closed with interrupted suture to control the skin tension for a good cosmetic result

\subsection{Complications and How to Avoid}

There are some complications that could be occurred associated with surgical technique in eyebrow keyhole approach.
1. Temporary or permanent supraorbital hypesthesia. In eyebrow keyhole craniotomy, the surgical field is very narrow, and medially the surgical field is limited by supraorbital notch that contains supraorbital nerve. Perioperative anatomical landmark should be prepared precisely to avoid damaging these structures. Certainly, keeping a distance of the craniotomy site at least 5-10 $\mathrm{mm}$ lateral to the orbital notch can reduce the risk of supraorbital nerve injury. Sometimes stretching the nerve during surgery is unavoidable, but preserving the nerve continuity will provide good chance to have functional recovery after surgery.

2. Frontal deformity. The frontobasal burr hole needs to be placed behind the temporal line after retracting the temporal muscle laterally. The burr hole site will be covered with the muscle to prevent deformity in this area. Proper repositioning of the bone flap is also an important step to prevent frontal deformity for a better cosmetic result. Bone flap should be fixed frontally and medially without any bony 
distance; make sure the mini plate tightly fixed the bone in proper position.

3. Suboptimal cosmetic result. Skin incision should be made within the eyebrow and follow the orbital rim. Retraction of the skin flap should be in gentle manner to prevent soft tissue necrosis, and it is better to minimize the use of bipolar cauterization during skin and soft tissue procedures. The skin is closed with interrupted suture to have an optimal skin tension with good approximation.

4. Infection. If the frontal sinus opened during procedure, careful repair is mandatory. The periosteum or fascia flap, bone wax, or abdominal fat tissue can be used to repair the injured sinus. Make sure the dura is closed watertightly with interrupted suture; if still dehiscence occurred, a small muscle patch should be used for this purpose.

\section{$2.5 \quad$ Limitations}

1. This approach is contraindicated in patient with massive brain swelling after subarachnoid hemorrhage.

2. This approach could not be a standard for all of aneurysm surgery; the indication should be strict and rely on the surgeon's experience.
3. The keyhole craniotomy may limit the microsurgery working angles, so it is mandatory to use a high magnification microscope and specific keyhole microsurgery instruments.

4. It is preferred not to use this approach for patient with large frontal sinus, because the greater risk of infection may occur.

\section{Bibliography}

1. Jallo GI, Bognar L. Eyebrow surgery: the supraciliary craniotomy: technical note. Neurosurgery. 2006;59:ONSE157-8.

2. Mori K. Keyhole concept in cerebral aneurysm clipping and tumor removal by the supraciliary lateral supraorbital approach. Asian J Neurosurg. 2014;9:14-20.

3. Ormond DR, Hadjipanayis CG. The supraorbital keyhole craniotomy through an eyebrow incision: its origins and evolution. Minim Invasive Surg. 2013;2013:1-11.

4. Paladino J, Mrak G, Miklic JH, Mihaljevic D. The keyhole concept in aneurysm surgery-a comparative study: keyhole versus standard craniotomy. Minim Invas Neurosurg. 2005;48:251-8.

5. Perneczky A, Reisch R. Keyhole approaches in neurosurgery, vol. 1. Concept and surgical technique. Wien: Springer; 2008.

6. Reisch R, Perneczky A. Ten-year experience with the supraorbital subfrontal approach through an eyebrow skin incision. Neurosurgery. 2005;57:ONS242-55.

Open Access This chapter is licensed under the terms of the Creative Commons Attribution 4.0 International License (http://creativecommons.org/licenses/by/4.0/), which permits use, sharing, adaptation, distribution and reproduction in any medium or format, as long as you give appropriate credit to the original author(s) and the source, provide a link to the Creative Commons license and indicate if changes were made.

The images or other third party material in this chapter are included in the chapter's Creative Commons license, unless indicated otherwise in a credit line to the material. If material is not included in the chapter's Creative Commons license and your intended use is not permitted by statutory regulation or exceeds the permitted use, you will need to obtain permission directly from the copyright holder. 